\title{
As mulheres na construção civil: algumas notas a partir de um trabalho de campo
}

Daniela Romcy $^{1}$

Jurema G. Brites ${ }^{2}$

Resumo: Este artigo tem por objetivo pensar os lugares das mulheres na construção civil, um mercado de trabalho visivelmente masculino, em que os homens ainda correspondem à maioria da mão de obra empregada. Partimos da dissertação de mestrado de Romcy (2013), intitulada: "Fala que nem homem": gênero e poder em uma obra da construção civil, onde, a partir de pesquisa etnográfica, realizada em um canteiro de obras localizado em uma cidade do interior do estado do Rio Grande do Sul/Brasil, foram estudados os conflitos e hierarquias daquele espaço entre uma engenheira e pedreiros, para pensar a masculinidade. Em um universo com cerca de trinta homens, havia nove mulheres: duas engenheiras, uma arquiteta, quatro responsáveis pela limpeza e duas pela alimentação dos empregados. Procuramos apresentar um pouco das interações destas mulheres na obra e em como elas foram importantes para pensar as relações de gênero neste espaço. Esta discussão se torna relevante na medida em que alguns dados vêm apontando um aumento das mulheres em todos os setores da construção civil.

Palavras-chave: trabalho; mulheres; construção civil

Mestre em Ciências Sociais pela Universidade Federal de Santa Maria - RS. daniromcy@gmail.com

2 Antropóloga e Professora de Departamento de Ciências Sociais e Humanas da Universidade Federal de Santa Maria - RS. juremagbrites@gmail.com.br 
Abstract: This article has the objective of analysing the place of women on civil construction, a job market visibly masculine, where men still correspond to the most utilized labour. We part from Romcy's master degree dissertation, entitled: "speak like a man": gender and power building site on civil construction, where, from the ethnographic method, performed on a jobsite localized in a country town in Rio Grande do Sul, the conflicts and hierarchies from that space between a female engineer and male bricklayers were studied, to analyse the masculinity. In a universe with about thirty men, there were nine women: two engineers, an architect, four responsible for cleanup and two for the feeding of the employees. I intend to present a bit of the interactions of these women and how they were important to examine the relations of gender in that space. This discussion turns relevant, insofar as some data point to the growing of women in all sectors of civil construction.

Key words: work; woman; civil construction

\section{Introdução}

O mercado da construção civil teve um crescimento significativo nos últimos anos. Esta eclosão, segundo o Estudo Setorial da Construção em 2012, realizada pelo Dieese (Departamento Intersindical de Estatística e Estudos Socioeconômicos) foi impulsionada pelo aumento dos investimentos públicos em obras de infraestrutura e em unidades habitacionais, a partir do lançamento de dois programas de governo: o Programa de Aceleração do Crescimento (PAC I), em 2007, e o Programa Minha Casa, Minha Vida (PMCMV), em 2009. Ainda segundo esse estudo, em 2010 foi registrado o melhor 
desempenho em 24 anos. Resultado este devido a uma combinação de fatores, dentre eles o aumento do crédito, a queda das taxas de juros, programas de investimentos públicos em infraestrutura, redução de impostos, aumento da renda dos ocupados e da massa de salários.

Segundo esse panorama, houve um incremento na demanda por mão de obra. $\mathrm{O}$ crescimento no setor acabou permitindo que as mulheres se inserissem, ou fossem inseridas também nessas ocupações, inclusive com incentivo a diversos programas de profissionalização e capacitação voltados especificamente para elas. Segundo registros do RAIS 2011 (Relação Anual de Informações Sociais) divulgados pelo Ministério do Trabalho, as mulheres com carteira assinada em todas as categorias tiveram um aumento de 5,93\%, e a construção civil aparece como responsável por uma porcentagem significativa desse crescimento entre os períodos de 2010 a 2011. Principalmente em setores como construção de estações e redes de telecomunicações, que onde a participação feminina passou de 12,96\% em 2010 para 13,68\% em 2011, na perfuração e construção de poços de água que passou de 11,75\% para 12,31\%; e ainda na Montagem e instalação de sistema e equipamentos de iluminação e sinalização em vias públicas, postos e aeroportos atividade onde a participação passou de 14,14\% em 2010 para 14,36\% em 2011.

Diante do panorama acima explicitado, voltamos nosso olhar para pensar esse mercado de trabalho ainda marcado como um espaço masculino, buscando aqui compreender de que forma essa inserção 
feminina vem se construindo. Para tanto utilizamos bibliografias sobre a inserção das mulheres pedreiras no mercado de trabalho, assim como a etnografia realizada por Romcy no ano de 2013, em uma cidade do interior do Rio Grande do Sul.

$\mathrm{Na}$ etnografia referida não havia mulheres contratadas como pedreiras, mas encontramos aproximações nas falas dos pedreiros pesquisados em 2013, assim como na literatura sobre mulheres pedreiras. E mais do que isso, independente do cargo ocupado pelas mulheres há invariavelmente uma aproximação linear aos padrões de gênero que corroboram estereótipos de como toda mulher é e/ou deve ser num ambiente repleto de homens.

Para nossa digressão aqui apresentaremos as mulheres da obra em dois blocos. Antes de criar uma dicotomia simples e superficial é importante esse olhar diferenciado, pois há aproximações e também diferenças entre estas mulheres, entretanto a questão de classe ainda faz com elas sejam tratadas de formas distintas, assim como muda a forma como elas se apresentam no ambiente de trabalho. Primeiramente apresentamos as mulheres que ocupam um cargo considerado de prestígio na nossa sociedade: duas engenheiras e uma arquiteta e posteriormente apresento as outras seis trabalhadoras: quatro responsáveis pela limpeza, e duas responsáveis pela alimentação dos pedreiros da obra. 


\section{Sobre mulheres e a construção civil}

Após alguns dados sobre mulheres e trabalhos que detém apreço social, apresentaremos neste subitem as engenheiras e a arquiteta: Fabiana (engenheira-chefe da obra), Flávia (chefe de engenharia, da rede da qual o ponto comercial pertence) Paula (arquiteta e fiscalizadora da obra), e as relações estabelecidas entre elas no local de trabalho. Posteriormente seguimos a mesma lógica com as faxineiras e cozinheiras e as especificidades que o contexto de trabalho onde predominam os homens dispõem.

Cristina Bruschini $(1999 ; 2000 ; 2007)$ realizou pesquisas sobre as ocupações profissionais femininas que possuem algum prestígio na nossa sociedade, tais como engenharia, direito, arquitetura e medicina. Em sua pesquisa realizada com dados da RAIS entre os anos de 1993 a 2004, a autora aponta um crescente aumento no campo de trabalho feminino no Brasil, dados esses que continuam crescendo segundo dados recentes do Ministério do Trabalho (2011). Na Magistratura, por exemplo, as mulheres ocupavam $22,5 \%$ dos postos de trabalho, em 1993 e em 2004 este índice chega a 34\%. Na arquitetura elas ocupavam, em 2004, 54\% de mão de obra feminina, ou seja, nestas categorias percebe-se um aumento significativo das mulheres no mercado de trabalho Entretanto, no caso das engenharias, as mulheres ocupavam 12\% dos cargos disponíveis em 1993 e esse índice cresceu apenas para $14 \%$ em 2004. Se comparada a outras ocupações, a carreira da 
engenharia é a que menos cresce em termos de mão de obra feminina, indicando o quanto esse universo é pouco permeável às tendências de feminilização do trabalho.

Segundo Bruschini (2007), há algumas diferenças e semelhanças entre homens e mulheres nas profissões por ela analisadas, por exemplo, que as mulheres são mais jovens do que seus colegas e que permanecem no emprego menos tempo do que os homens. $\mathrm{Na}$ magistratura, há uma tendência a que as mulheres trabalhem mais no setor público, o que não se verifica nas outras profissões. Com relação ao tamanho do estabelecimento e às jornadas de trabalho, há uma semelhança entre os gêneros.

Sua conclusão é que, apesar do aumento das mulheres nessas profissões de prestígio na nossa sociedade, os padrões de gênero presente em quase todo o mercado de trabalho, por ela estudados, se repetem e persistem. Um dos exemplos apontados pela autora se refere à questão salarial, já que as mulheres ainda recebiam e recebem, ainda hoje, menos do que os homens.

No caso das engenharias, a presença feminina altera-se significativamente considerando as especialidades e o local em que os/as profissionais desempenharão suas atividades; por exemplo, nos trabalhos de implantação de infraestrutura, a céu aberto, a presença de mulheres é pequena, o que é diferentemente observado nas atividades de industrialização, realizado em espaços fechados. 
$\mathrm{Na}$ época da realização da pesquisa, Romcy tentou contato com várias construtoras e pessoas de sua rede de sociabilidade, para mapear as mulheres que exerciam a engenharia na localidade $\mathrm{e}$ trabalhassem diretamente com homens "fora" do escritório. Esse tipo de profissional era raro nesta região, ou seja, que não havia muitas mulheres em obras, a maior parte das engenheiras que encontrava trabalhava na área administrativa: no escritório das empresas ou na função de elaboração de projetos, e poucas na execução e acompanhamento da obra. A dificuldade de uma mulher que se forma em engenharia e tem predileção por canteiros de obras também é uma realidade, conforme Fabiana relatou:

"Sabe, me formei em 2001 e eu sempre adorei o canteiro de obras, toda minha formação foi nesse sentido. Inclusive meu estágio foi nesta área em uma reforma de grande porte em Porto Alegre. Mas eu passei muito tempo procurando emprego, foi difícil, pois a preferência inegavelmente é por homens. Em algumas entrevistas isso ficava nas entrelinhas. Em outras era bem direto, teve empregador que chegou a me dizer claramente que o meu currículo era ótimo, que eu era qualificada para o cargo, mas que a empresa preferia a contratação de um homem." (diário de campo)

Ainda que a condição da mulher seja difícil em um mundo do trabalho demasiadamente calcado em uma matriz heterossexual ${ }^{3}$, sua

3 A matriz heterossexual garante a manutenção da ordem compulsória do sexo/gênero/desejo, que determina que o órgão sexual definirá a identidade de gênero 143 
condição de gênero é exacerbada por outro fator que invoca desconforto aos empregadores: a maternidade. Engravidar e ser a principal, quando não a única cuidadora das crianças, ainda aparece como uma dificuldade real para a mulher que trabalha fora de casa. Fabiana comprovou isso na segunda gestação, quando foi demitida após retornar da licença maternidade. Ainda que alguns dados como os da Fundação Carlos Chagas (2007) pontuem que o trabalho tenha se tornado tão importante para as mulheres quanto à decisão de conceber e o cuidar de filhos, a manutenção do modelo de divisão sexual do trabalho no qual a mulher é a responsável pelo mundo doméstico limita seu espaço no mercado de trabalho, pois os próprios empregadores consideram que a atenção dispensada à família diminui a produtividade da mulher trabalhadora, pois esta acumula funções de trabalho externo somada às funções domésticas (BURSCHINI, 2000).

Neste caso específico, Fabiana trabalhava em uma cidade distante da qual morava, o que a obrigava a deixar seu filho aos cuidados do pai, mas não só dele, também sua mãe era requisitada como o "apoio" fundamental para que ela pudesse desempenhar bem o seu papel no trabalho na empresa de engenharia. $\mathrm{O}$ cuidado de familiares aparece aqui como uma faculdade essencialmente feminina, que os homens não podem executar sozinhos.

\footnotetext{
e o desejo sempre heterossexual. Onde sexualidade e gênero aparecem como normas estáveis definindo a condição social tanto para homens, quanto para mulheres, corroborando as formas binárias de macho/fêmea; homem/mulher; masculino/feminino; pênis/vagina.
} 
Saindo do espaço privado para o público, Fabiana era metódica e como ritual de trabalho, todo dia ao chegar à obra, a engenheira dirigia-se primeiramente a Ricardo - mestre de obras - perguntando o que havia sido feito na sua ausência; sobre alguns problemas ocorridos; ou seja, tomava com ele algumas informações gerais sobre o andamento da obra. Em seguida inspecionava a obra, olhava principalmente a partir dos relatos de Ricardo, e se dirigia à cafeteria do estabelecimento para tomar seu café da manhã, geralmente com Ricardo e Taislan (ambos mestres de obras).

Flávia, chefe da empresa comercial que contratou os serviços da construtora, era ela a responsável por todo o andamento da obra não só daquele estabelecimento, mas das obras de toda a rede de estabelecimentos do qual o estabelecimento que pesquisei fazia parte. Ela aparecia na obra somente para as reuniões gerais entre construtora e estabelecimento, reuniões essas que ocorriam em uma sala fechada na própria companhia. Sempre depois de uma dessas reuniões que ocorriam esporadicamente, seu nome aparecia de modo depreciativo ou nas reclamações, principalmente dos mestres de obras e de Luís - um dos sócios da construtora. Ela era a responsável por cobrar e alterar o cronograma e os ajustes que ocorriam de forma imprevista durante o processo de andamento da reforma. Cobrava "tintim por tintim" o que estava nos projetos, e não gostava de alterações, o quê, segundo a engenheira Fabiana, era impossível de não acontecer, porque sempre 
ocorria falta de entrega de um fornecedor, ou mesmo aspectos climáticos que atrasavam a execução.

Assim como Flávia, Paula, a arquiteta, era uma profissional de outra empresa que foi ao mesmo tempo contratada pelo estabelecimento comercial como responsável pela fiscalização da obra. Ela aparecia de forma depreciativa nas falas dos homens e da própria engenheira Fabiana. Diferentemente de Fabiana, Paula era mais jovial em seu modo de vestir-se; usava sempre roupas confortáveis - mas que marcavam o seu status social de classe média - calça jeans, blusas joviais e sofisticadas. Estava sempre na correria e era mais nova e menos experiente do que Fabiana. Aquela era a sua primeira obra de fiscalização, pois havia se formado há pouco, o que, por si só, gerava desconfiança nos seus "fiscalizados".

As falas negativas que Romcy escutava dos pesquisados, principalmente sobre sua inexperiência e sua rabugice, foram justamente o que proporcionou o entendimento sobre a dinâmica das relações daquele espaço específico, assim como das hierarquias próprias da construção civil. Assim, mesmo que tenha aparecido pouco na obra, esses momentos, quando aconteciam, foram importantes para pensarmos a lógica do grupo. Sua rotina na obra era um pouco semelhante à de Fabiana. Assim que Paula chagava, percorria todas as partes onde as reformas estavam sendo feitas, conversando pontualmente com pedreiros, e logo após se dirigia ao contêiner da administração para falar com os responsáveis pelo serviço, Luís, 
Ricardo e Fabiana. Suas perguntas eram sempre pontuais e ríspidas: sobre o andamento do projeto, sobre os fornecedores, se as datas de entrega do material estavam todas como programado. Seu rosto permanecia sempre sério; quando sorria, seu sorriso era quase "amarelo" ou receoso, como o de alguém que não estava muito disposto a participar de conversas descontraídas. Sua presença ali não durava mais do que duas horas.

A forma como ela expressava as suas observações sobre o progresso da obra aliada ao seu pouco tempo no emprego geravam nos trabalhadores certa desconfiança da sua capacidade real de conhecer uma obra na prática. Sempre que ela se queixava de que algo tinha sido feito errado, como, por exemplo, um cano que foi colocado em lugar diferente do que o que estava descrito no projeto, Ricardo frisava que ela não sabia nada de obras; que as coisas na obra nem sempre conseguiam ocorrer conforme o planejamento do projeto; que ela não podia levar tudo "ao pé da letra"; que poderia ser mais flexível.

Percebemos que a forma como ela se expressava fazia parte do seu ofício enquanto fiscalizadora, pois seu trabalho era justamente dar ordem, exigir, cobrar - ações e formas, que não eram bem vistas, sobretudo pelos homens. Como eles consideravam essas ações negativas, estendiam tais características para a própria pessoa, considerando uma pessoa "patricinha" $a^{4}$ " chata". Eles reclamavam ou

\footnotetext{
${ }^{4}$ Patricinha é uma descrição pejorativa da linguagem coloquial que denota futilidade e consumismo de quem apresenta este perfil.
} 
debochavam da roupa, do cabelo, da cidade onde ela morava, da sua maneira falar, ou seja, depreciavam-na em todas as oportunidades. Enquanto isso, na sua frente, os homens com os quais ela conversava que ficavam basicamente no contêiner administrativo - mostravam subserviência e escutavam com atenção seus apontamentos, assim que ela se retirava, eram feitos os comentários e reclamações apontados na descrição acima.

Esses momentos podem ser refletidos a partir dos conceitos de roteiros encobertos de Brites (2000 apud SCOTT,1985), entendidos como performances de todo e qualquer subalterno que, por não poder enfrentar o dominante, neste caso Paula, o faz na retaguarda, dissimuladamente; pois à sua frente fingem obedecê-la, enquanto enfraquecem sua autoridade falando dela de forma negativa quando não está presente.

Embora representasse um cargo de autoridade, a forma como ela desempenhava o comando atrelado ao modo como era compreendida pela maioria das pessoas que trabalhavam naquela obra a colocava em um lugar de não pertencimento, criando um claro distanciamento ou uma ausência de vínculo com o resto do grupo. Outra forma de não pertencimento pode ser pensada pela oposição entre trabalho manual e trabalho intelectual, já que Paula acabara de sair da faculdade com todo o conhecimento da teoria, mas com pouco conhecimento do dia a dia de um canteiro de obras. Segundo Ricardo, 
na construção civil o aprendizado se dá no cotidiano, e não nas "cadeiras da universidade".

Mas o que realmente ficava aparente era que ela não conhecia o código cultural daquele espaço. Apesar de ser superior na relação de trabalho, ela parecia não entender o jogo cultural de gênero, pois naquele universo mulher não pode afrontar explicitamente a autoridade masculina, e mesmo os homens que mandam têm que saber como fazêlo. Nestes contatos - de Paula com o grupo de operários, mestres de obra e com a engenheira encarregada da construção - ficava visível um distanciamento cultural de classe e gênero. Enquanto a engenheira Fabiana parecia comportar-se como um "mediador cultural"5, pois embora pertencesse a um extrato de classe social superior da maioria dos trabalhadores da obra e ser mulher sabia como se comportar para garantir o respeito.

Diferentemente de Paula, fomos reconhecendo que, embora Fabiana trabalhasse em todos os locais da obra, a sua fala era restrita a determinadas pessoas, como o sócio da empresa, o mestre de obra, os responsáveis pela elétrica/hidráulica/pintura. Ricardo, mestre de obras, era com quem ela mais conversava, com isso deixava claro que entendia as hierarquias do campo. Dirigindo-se pouco aos pedreiros, e quando isso ocorria era em tom ameno e como um aviso, jamais em tom de

\footnotetext{
5 Karina Kuschnir e Gilberto Velho. Segundo os autores, os mediadores aceleram a comunicação, são intermediários entre mundos diferenciados, tradutores das diferenças culturais.
} 
ordem, estes momentos apareciam quando eles não estavam trabalhando, ou quando não estavam usando os EPI (Equipamentos de Proteção Individual: capacetes, botas, protetores auditivos), ou seja, as ordens significativas e mais enérgicas nunca eram dadas diretamente aos pedreiros. Ela acionava Ricardo, que comunicava o que deveria ser feito aos trabalhadores e mesmo com Ricardo não eram ordens que Fabiana comunicava, transformava sua autoridade de engenheira responsável pela execução da reforma em sugestões e/ ou combinações de como realizar tarefas em parceria de equipe. Dessa forma atenuava seu lugar de mando entre os homens. Diferentemente das críticas que Paula recebia, Fabiana era uma colega muito apreciada por todos na obra, pessoa que os rapazes da obra confiavam e até mesmo tentavam proteger.

\section{Responsáveis pela faxina e pela alimentação}

Dentre todas as mulheres descritas, as faxineiras e as cozinheiras foram realmente eclipsadas na pesquisa de campo, a ponto de eu não saber nem seus nomes. Elas fugiram muito do meu olhar, pois eu ainda estava presa aos condicionamentos de um olhar generado e de classe, prendendo-me de forma demasiada a um objeto idealmente construído. Em outras palavras, eu procurava o tempo todo compreender as relações dos pedreiros e de sua chefe engenheira. Essa certa "obsessão" por um objeto enturvava meu olhar para as outras personagens presentes nas 
cenas de campo; fato que pude elucidar a partir das análises dos diários e da construção da escrita etnográfica. Todavia, também constatei que essas mulheres também eram invisibilizadas pelos homens (Romcy, 2013, pg. 55)

A presença das mulheres na obra, como veremos, ainda que cada vez mais incorporadas, comportam alguma coisa de anômalo. O canteiro de obras é construído simbolicamente como um espaço masculino - lugar embrutecido, com tarefas pesadas e que resultam em muita sujeira na sua execução; que exigem força física e exposição às intempéries da natureza. Mesmo o planejamento e projeto que são tarefas menos manuais são identificados com a capacidade racional estratégica, na cultura ocidental tradicional pensada como habilidade masculina, assim o trabalho das mulheres até bem pouco tempo era imprevisto ou invisível, como procuraremos mostrar a seguir.

Quatro mulheres trabalhavam como responsáveis pela limpeza, duas no turno da manhã e duas à tarde. Três delas tinham mais de quarenta e cinco anos e a mais jovem tinha em torno de trinta anos. Trabalhavam de uniforme - um macacão azul - e com os EPI's. Todo dia, ao chegar, dirigiam-se até o contêiner administrativo para pegar a chave da sala onde se encontravam os materiais de limpeza.

Eram responsáveis pela limpeza da sujeira deixada pelos trabalhadores da obra, geralmente elas trabalhavam em lugares opostos aos pedreiros; assim que estes acabavam a reforma, terminando uma 
seção, elas se dirigiam a esse espaço para deixá-lo "apresentável", já que o estabelecimento não fechou em nenhum momento durante a reforma. Assim, tinham como tarefa deixar, quanto fosse possível, a presença da reestruturação imperceptível.

As cozinheiras foram contatadas para trabalhar na "casa masculina", casa esta que a construtora alugava perto do local de trabalho, a qual servia de moradia para pedreiros vindos de outras cidades e durante o meio dia era usada como refeitório para todos os trabalhadores. Era notório que essas mulheres não se espalhavam nos espaços da casa, o que pudemos notar é que elas ficavam circunscritas ao espaço da cozinha e da sala principal. A relação delas com os homens restringiam-se aos seus chefes, mais especificamente a Ricardo e a Luis.

Pensando nas descrições acima, podemos perceber que são diversos os fatores que tornam essas mulheres invisibilizadas nesse contexto. Todas elas em certa medida possuem inscrições de subalternidade de gênero, ocupando papeis tradicionalmente femininos nas relações de trabalho.

E é justamente neste sentido que podemos aproximar essas mulheres das mulheres que foram analisadas em outros trabalhos cujo enfoque as relações de trabalho na construção civil a partir de pedreiras. Em A construção civil - Isso é coisa de mulher, Silva (2013) discorre a partir da fala de um dirigente sindical, que as mulheres eram contratadas para trabalhar na construção civil para limpar a sujeira 
deixada pelos trabalhadores, somente posteriormente é que passaram a realizar atividades, tais como emassamento de cerâmica, pintura e finalizações em geral.

Para pensar a inserção destas mulheres, temos que levar em consideração que ela se dá em lugares tipicamente ligados ao universo feminino. Como aponta a pesquisa da autora acima citada, há uma quantidade expressiva de mulheres que trabalham como serventes e cujas responsabilidades são somente limpar e assentar a cerâmica. A própria autora encontrou apenas duas mulheres que trabalhavam como pedreiras, mas mesmo entre elas somente uma desempenhava a função, cabendo à outra o papel da limpeza.

$\mathrm{Na}$ etnografia de Romcy uma conversa que teve com Alex, chefe da hidráulica, é significativa para esta reflexão:

Em um dado momento eu estava descansando, comendo algo da lanchonete, e Alex se aproximou, perguntando se poderia sentar comigo; concordei. Ambos estávamos interessados no jogo que passava na televisão. Achei uma hora oportuna para perguntar se ele já havia trabalhado com mulheres pedreiras:

- Mas me conta Alex, como sei que tu trabalhas há mais de vinte e cinco anos neste serviço, tu já trabalhou com mulheres que desempenhavam a mesma função de um pedreiro?

- Ah, Dani, já trabalhei sim, mas não com muitas. Tu sabe o que eu prefiro. Eu acho que os guris se comportam mais, respeitam, sabe? Não ficam de conversa mole, ou de zoação. 
- Sei, e como elas eram no trabalho? Trabalhavam pesado?

- Tu sabe que pegavam, trabalhavam bastante. Mas não são muitas não. Como eu te falei, agora tá começando a aparecer mais, eu já trabalhei com algumas. Só que elas não trabalham que nem a gente não. Ficam com a parte mais delicada, de finalização, mesmo. No rejunte ou na pintura. Porque mulher faz melhor esse serviço, né?

- Seu Alex, sei não. Se me colocarem pra fazer serviço delicado eu não vou me sair bem. Limpo minha casa porque preciso, mas não gosto do serviço não. E nem sei fazer isso bem.

Alex pareceu não escutar o que eu estava falando. Olhou para a televisão, comentou algo sobre o jogo, se despediu e voltou ao serviço. (diário de campo)

Este relato pode demonstrar a impossibilidade de pensar as mulheres a partir de outros paradigmas, ratificando que para esse universo de trabalhadores, ou talvez ele seja reflexo de alguns grupos sociais, o mundo é dividido entre homens e suas características tais como virilidade e força, e mulheres que carregam marcas da delicadeza e jeito para lidar com o universo doméstico.

Desvincular esses estereótipos de coisas de homens e coisas de mulheres foi central nos estudos de Mead nos livros Sexo $e$ Temperamento (2006) e Adolescência, Sexo y Cultura en Samoa (1985). Nesses trabalhos, principalmente em Sexo e Temperamento, a autora mostra que as características aprendidas na cultura que imputamos a homens e a mulheres, na verdade, são construídos socialmente e o que 
deseja explicitar a partir de três comunidades tribais, é a desconstrução da ideia, essencializada na nossa sociedade, de que homens e mulheres deveriam seguir padrões inatos de comportamentos generados. Ou seja, se naquele período atrelávamos a delicadeza à mulher e ao universo feminino, e vinculávamos ao homem a agressividade e ao mundo masculino - pensamento que ainda tem resquícios no universo do senso comum, podendo ser visualizado empiricamente na pesquisa de Romcy que reportamos neste artigo -, Mead nos mostra, em uma pesquisa transcultural, como aprendemos através da educação a exercer um determinado modelo de comportamento e que gênero não está preso à biologia, possuindo formas diversas de expressar as identidades sexuais.

Se em Mead o conceito de gênero ainda não aparece, é em 1975 com Rubin, no ensaio El tráfico de mujeres: notas sobre a "economia política" del sexo, o termo é introduzido nos estudos feministas. Neste texto, em crítica ao modo como autores paradigmáticos (como Marx, Lévi-Strauss e Freud) veem a mulher, procura explicar a opressão das mulheres a partir do engendramento do que nomeia "sistema sexo e gênero":: "el conjunto de disposíciones por el que una sociedad transforma la sexualidad biológica em productos de la atividad humana, y en el qual se satisfacen esas necesídades humanas transformadas" ${ }^{6}$ (Rubin, 1986, p.97).

\footnotetext{
6 "conjunto de disposições através do qual uma sociedade transforma a sexualidade biológica em produtos da atividade humana, e na qual estas necessidades transformadas são satisfeitas" tradução livre da autora.
} 
O sistema sexo-gênero, portanto, consiste em uma gramática, segundo a qual a sexualidade humana é transformada pela atividade humana. Segundo Adriana Piscitelli (2003), a autora Rubin foi de central importância para o debate feminista quando propôs pensar as mulheres como construções sociais a partir da totalidade dos sistemas culturais, diferenciando-se dos trabalhos feministas que delimitavam as análises especificamente às mulheres, ignorando este contexto mais amplo dos sistemas culturais. Ao mesmo tempo, mostrou como o sistema sexo-gênero se configura como produtor das relações de poder e também em como as categorias científicas estão atreladas a esse sistema.

Em Scott (1995), a definição da categoria de gênero repousa sobre a relação fundamental entre duas proposições: gênero é "um elemento constitutivo das relações sociais, baseadas nas diferenças percebidas entre os sexos e mais, o gênero é uma forma primeira de dar significado às relações de poder", e que estas relações hierarquizam, a partir das diferenças sexuais, modos de pensar que são duais e engessados. Ao invés de aceitar as relações binárias como naturais, a partir dessas autoras deve-se entender os processos e contextos por meio dos quais se constroem as hierarquias dos gêneros.

Pensando assim, mesmo quando ocorre uma "inversão" nas posições de chefia, como no caso de Fabiana, Flávia e Paula, a autoridade não pode se exercer sem passar pela dominação masculina. Em um ambiente extremamente masculinizado, quando o trabalho da 
mulher surge ou ele é invisibilizado (como no caso das faxineiras e cozinheiras) ou ele é endereçado a tarefas e espaços considerados menos masculinos dentro da obra (azulejistas, finalizadora de detalhes) ou no caso de exercerem algum tipo de chefia, ela somente será realmente respeitável se o fizer dentro dos códigos de conduta masculinos, sem ofender, sem gritar, sem mandar explicitamente e preferencialmente, como Fabiana sempre fez, passando pelo crivo e mediação dos outros homens da obra.

Mas não é somente com os demais homens da obra que as mulheres precisam se preocupar, uma dificuldade apontada pelo trabalho de Silva (2013) é o impasse que as mulheres de sua pesquisa tinham com os seus companheiros e maridos. Havia uma desconfiança no fato de que seus ambientes de trabalho eram constituídos preponderantemente por homens e isso poderia acarretar inclusive, como visto na pesquisa de Romcy, a opção destas mulheres por abandonar o emprego.

Duas semanas antes da reforma terminar, em uma segunda-feira de tempo nublado, eu cheguei ao ponto comercial cedo, como de costume, e avistei os mestres de obras conversando com dois pedreiros, todos próximos ao contêiner administrativo em volta da automóvel (Kombi) da empresa. Estranhei aquela cena, mas não dei muita importância; cumprimentei todos eles com um bom dia e me dirigi, como fazia costumeiramente, para guardar os meus pertences no container da administração. Ao chegar, notei que a porta estava fechada, o que não era normal, já que já 
havia vários trabalhadores ali. Mas como já havia acontecido antes de eu chegar lá e o container estar fechado, empurrei a porta para ter certeza. Ao fazer isso avistei Luís e Fabiana com caras sérias. No momento em que me avistaram pararam abruptamente de falar, logicamente eu percebi o mal estar, pedi desculpas e, como já havia interrompido, perguntei se eu podia somente deixar meus pertences ali que eu já ia me retirar, o que fiz com certa rapidez, pois senti o clima estranho.

Um pouco depois disso Fabiana saiu do contêiner e veio falar comigo. Calma, ela me informou que estava saindo, que havia conversado com Luís e que iria continuar na empresa, mas na capital, onde ficaria perto de sua família, contudo que eu não me preocupasse, pois se quisesse poderia continuar minha pesquisa até o final, mesmo sem que ela estivesse mais ali. Mostrou-se bem preocupada e até um pouco triste por deixar a obra quase no final, mas segundo suas palavras teve que escolher: "ou ela ficava com o emprego, ou com o casamento". Pediu desculpas novamente e seguiu em direção ao hotel para pegar suas coisas e ir embora (Romcy, 2013, pg 92/93).

\section{Considerações Finais}

Ao todo, podemos perceber que há limitações no campo de trabalho das mulheres que procuramos descrever, e que não são específicos somente delas, mas se constituem como marcas da relação entre mercado de trabalho e mulheres. Entretanto, o fato de trabalharem num contexto tipicamente masculino produz outras configurações a esse grupo. 
Como tentamos demonstrar ao longo do artigo a partir de alguns dados e do meu trabalho de campo, as mulheres estão se inserindo gradualmente em lugares que até pouco tempo eram nichos masculinos, sendo o trabalho o principal espaço social da produção da identidade masculina (GROSSI, 2004). Os dados são crescentes, mesmo que esta conjuntura seja mais tímida do que em outras profissões e sejam colaboradas pelo aumento da demanda nos serviços.

Os lugares ocupados pelas mulheres que trabalham como serventes ou pedreiras ainda estão ligados ao que comumente se convencionou atrelar a elas, espaços da casa, do privado, como a limpeza e atividades que exijam maior detalhamento (BRITES, 2000). Mas fugindo da uma lógica vitimizante, é a partir destes espaços que elas mudam suas vidas e conseguem maior autonomia, como aponta a pesquisa de Silva (2013) ao verificar que essas mulheres têm assim o aumento do seu poder aquisitivo e esse é um dos fatores primordiais para a escolha de emprego neste segmento.

No caso da engenharia, emprego que costumamos denominar como de prestígio na nossa sociedade, quando olhamos exclusivamente para engenheiras e arquitetas podemos pensar neste caso específico há uma inversão de classe e de gênero, já que a mulher se torna chefe de tantos homens, sem cair em uma essencialização do conceito. Consideramos que há indicações de que elas provocam uma desestabilização nas normas de gênero, mesmo que de formas distintas. Se analisarmos o caso de Fabiana que com sua leitura do campo de 
disputas buscou não romper com a lógica da dominação masculina, consideramos que ela adotou essa atitude como forma de ter sua autoridade respeitada, ao mesmo tempo em que também tornou-se digna de algum grau de afetividade e admiração dos trabalhadores. Já as mulheres que alteram estas relações, como Paula e Flávia, não são respeitadas em um canteiro de obras. Cabe destacar que esta foi a conjuntura que observamos e que pode sim haver outras configurações diversas, mas acreditamos que ela é significativa para refletir sobre as relações de gênero num contexto mais amplo, ou mesmo em outras realidades.

É ainda preciso destacar que a realidade da presença das mulheres na construção civil não ocorre de forma tranquila e sem conflitos, pois é difícil a busca de igualdade de gênero quando as lógicas da diferença calcadas na hierarquia estão impregnadas em alguns grupos da sociedade, frutos do processo de educação em que esses indivíduos foram socializados. 


\section{Referências}

BOURDIEU, Pierre. A Dominação Masculina. Rio de Janeiro: Bertrand Brasil, 2010.

BRITES, Jurema Gorski. Cinderela Domesticada. Um estudo sobre saberes femininos que circulam entre empregadas domésticas e seus empregadores. Porto Alegre: Relatório Final apresentado à FCC, II Programa de Incentivo e Formação em Pesquisa sobre a Mulher, 1997.

- Afeto, desigualdade e rebeldia: bastidores do serviço doméstico. 2000. 239 f. Tese (Doutorado em Antropologia Social). Universidade Federal do Rio Grande do Sul, Porto Alegre, 2000. - Afeto e desigualdade: Gênero, geração e classe entre empregadas domésticas e seus empregadores. Cadernos Pagu, ${ }^{\circ}$ 29, Jul/Dez, 2007. p. 91-109

; MOTTA, Flávia de Mattos. (orgs). Introdução. In:

Etnografia o Espírito da antropologia. (manuscrito)

BRUSCHINI, Cristina. Médicas, arquitetas, advogadas e engenheiras: mulheres em carreiras profissionais de prestígio. Revista Estudos Feministas, v. 7, n. 1/2, p.9-24, 1999.

; LOMBARDI, Maria Rosa. Bipolaridade do trabalho feminino no Brasil contemporâneo. Cadernos de Pesquisa, n.110, p.67-104, jul. 2000.

. Trabalho e gênero no Brasil nos últimos dez anos. Cadernos de Pesquisa, v. 37, n. 132, p. 537-572, set./dez. 2007. 
, COSTA, Albertina de Oliveira Costa. Uma questão de gênero (Org.). Rio de Janeiro: Rosa dos Tempos; São Paulo: Fundação Carlos Chagas, 1992.

BUTLER, Judith. Problemas de Gênero, Rio de Janeiro, Editora Record, 2003.

DAMATTA, Roberto. A Casa e a Rua: Espaço, cidadania, mulher e morte no Brasil. Rio de Janeiro, Editora Guanabara, 1987.

DUARTE, Luiz Fernando Dias. Identidade Social e padrões de agressividade verbal em um grupo de trabalhadores urbanos. In José Sérgio Leite Lopes (org.) Cultura e Identidade Operária: aspectos da cultura da classe trabalhadora. Rio de Janeiro: UFRJ/PROED, 1987.

FONSECA, Cláudia. Quando cada caso NÃO é um caso: Pesquisa etnográfica e educação. Revista Brasileira de Educação. n. 10, p. 5878, 1999.

. Família, Fofoca e Honra: etnografia de relações de gênero e violência em grupos populares. Porto Alegre: Ed. UFRGS, 2000.

FUNDAÇÃO CARLOS CHAGAS. Mulheres, trabalho e família. Banco de dados sobre o trabalho das mulheres, série 2, 2007.

GEERTZ, Clifford. A Interpretação das Culturas. Rio de Janeiro: $L T C, 1989$.

GROSSI, Miriam Pillar. Masculinidades: uma revisão teórica. Antropologia em primeira mão. Florianópolis, 2004. P. 4-37 
INSTITUTO BRASILEIRO DE GEOGRAFIA E ESTATÍSTICA IBGE. Pesquisa mensal de emprego (Mulher no mercado de trabalho: perguntas e respostas - boletim especial -Dia Internacional da Mulher). Rio de Janeiro: 2012.

KUSCHNIR, Karina; VELHO, Gilberto.(org.). Mediação, cultura e política. Rio de Janeiro: Aeroplano, 2001.

MEAD, Margaret. Sexo e temperamento. São Paulo: Perspectiva, 2006.

. Adolescência, sexo y cultura en Samoa. Barcelona: Planeta De Agostini, 1985.

MORAIS, Maria Lygia Quartim de. Usos e limites da categoria gênero. Cadernos Pagu, Campinas, n.11, p.99-105, 1998.

Relação Anual de Informações Sociais 2011. Brasília, Ministério do Trabalho, 2011.

ROMCY, Daniela. Fala que nem homem: Gênero poder e honra em um canteiro de obras. 2013. Dissertação (Mestrado em Ciências Sociais), Universidade Federal de Santa Maria, Santa Maria, 2010.

RUBIN, Gayle. El tráfico de mujeres: notas sobre a economia política"del sexo. Nueva Antropologia, México, v. VIII, n. 30, p. 95$145,1986$.

SAFFIOTI, Heleieth I. B.. Posfacio: conceituando gênero. In: SAFFIOTI, Heleieth I. B.; MUÑOZ-VARGAS, Mônica. (orgs.) 
Mulher brasileira é assim. Rio de Janeiro: Rosa dos Ventos, 1994.p 271-281.

SCOTT, Joan. Gênero uma categoria de análise útil de análise histórica. Revista Educação \& Realidade, Porto Alegre, v. 20, n 2, p. 71-99, jul/dez. 1995.

SILVA, Mayara Raquel, Construção civil: "Isso é coisa de mulher?”. $9^{\circ}$ Prêmio Construindo a Igualdade de Gênero - Redações, artigos científicos e projetos pedagógicos premiados - 2013. Brasília: Presidência da República, Secretaria de Políticas para as Mulheres, 2013. p. 58-87. 